\title{
Universal Access: The challenges ahead
}

\author{
Simeon Keates ${ }^{1[0000-0002-2826-672 X]}$ \\ ${ }^{1}$ Edinburgh Napier University, 10 Colinton Rd, Edinburgh. EH10 5DT United Kingdom \\ s.keates@napier.ac.uk
}

\begin{abstract}
It is approaching 20 years since the first issue of the International Journal on Universal Access was published and also that the first International Conference on Universal Access in Human-Computer Interaction was held. This paper reflects on how the field of Universal Access has evolved over the intervening period and proposes new areas of research challenges that have either emerged following recent advances in technology or still remain comparatively poorly addressed. The proposed challenges have been derived from a examining Maslow's Hierarchy of Needs along with technological development trends.
\end{abstract}

Keywords: Universal Access, inclusive design, artificial intelligence, robots, healthcare, telehealth, cybersecurity, networks, functional impairments, rehabilitation engineering

\section{Introduction}

It is approaching 20 years since Springer published the first issue of the International Journal on Universal Access in the Information Society in 2001. That was the same year that the inaugural Universal Access and Human-Computer Interaction conference was held in New Orleans. While a $20^{\text {th }}$ anniversary issue is being prepared, it is interesting to consider how far the field has come in that time and consider where it might be heading over the next 20 years.

\subsection{Where were we in 2001?}

It is interesting to take a look at the topics of the first issue of the UAIS journal.

The first paper addressed the use of speech recognition software by both ablebodied users and those with spinal cord injuries [1] and evaluated its usefulness based on user productivity and satisfaction. The authors expressed their dissatisfaction with more traditional analyses of the acceptability of software for users with functional impairments.

The second paper focused on developing a model-based schema for representing roles and goals when considering "Design for All" [2]. The aim of the paper was to explore a method for capturing and representing user behaviours more completely so that more effective solutions for the widest possible range of users could be developed. 
Next was a paper that focused on the use of biometric processing to better identify users and their needs [3]. The aim was to identify and respond to users more efficiently and securely.

The penultimate paper proposed that accessibility and high quality of interaction with products, applications, and services by anyone, anywhere, and at any time are fundamental requirements for universal access [4]. The paper discussed how these concepts could be utilised in the development of user interfaces that adapt automatically to the needs of the users.

Finally, the first issue concluded with a paper that looked at the development of user models and a framework to enable user interface developers to be able to respond better to the wider range of users [5].

These topics have been visited and re-visited a number of times further over the 18 years since that first issue. Jumping ahead to the present day, it is clear to see that if the next issue of the UAIS journal came out with an identical table of contents, many readers would not be surprised. That original table of contents would still be as valid today as it was back in 2001, albeit that much of the underlying technology platforms would be more advanced. So what does this tell us about progress in universal access for the past 20 years or so?

\subsection{What has changed since 2001?}

As discussed above, technology has clearly advanced since 2001. The Internet, already popular back then, is now ubiquitous. This has now expanded to include the Internet of Things, i.e. collections of smart devices and sensors that are able to communicate with each other in both formal and ad hoc networks.

Mobile telephone networks are now capable of supporting much greater bit rates. Coupled with the increase in raw processing power of modern microchips and better battery life with the latest generation of battery cells, the modern smartphone is now at least as capable as many desktop computers from 2001. Tablet computers, such as the iPad, offer new methods of interacting with technology on the move, including multi-point touch. The very nature of we interact with each other is changing, too. We are in the age of the always-on and always-connected citizen. Social media may be evolving from one preferred platform to another every few years, but its overall popularity is still very strong.

Augmented reality displays are now commonplace in cars and aeroplanes. Voice activated systems can be used to control your house or play your choice of music. Even the humble doorbell can be upgraded to offer a form of virtual presence allowing a homeowner to talk to someone on their doorstep via their mobile phone.

Cars are on the cusp of becoming self-driving. Many aeroplanes are capable of flying themselves to their destinations. Companies are exploring the use of drones for delivering parcels to private addresses. Warehouses and factories are continuing to become almost fully automated. Table 1 gives a number of other interesting technological milestones from the intervening period. 
Table 1. A summary of a few notable milestones since 2001.

\begin{tabular}{ll}
\hline Date & Technology milestone \\
\hline June 2007 & Launch of the iPhone \\
July 2008 & Launch of the App Store \\
January 2010 & Launch of the Parrot Ar.Drone \\
April 2010 & Launch of the iPad \\
February 2011 & IBM Watson competes in Jeopardy! \\
October 2011 & Launch of Siri \\
February 2012 & Launch of Raspberry Pi \\
April 2012 & Launch of Google Glass \\
April 2015 & Launch of Apple Watch \\
\hline
\end{tabular}

All of these technological advances offer significant opportunities for everyone, regardless of any personal functional impairment(s). There have also been many societal changes. Back in 2001, very few countries had legislation guaranteeing equal rights of access for people with disabilities. The USA had its 1990 Americans with Disabilities Act [6] and the UK had the 1996 Disability Discrimination Act [7], but there were very few other countries that had comparable laws. As we approach 2020, though, the rights of people with disabilities are upheld much more widely, for example with the UN Convention on the Rights of Persons with Disabilities (CRPD) adopted in 2006 [8].

Issues around accessibility and universal access have also become increasingly incorporated into academic conference calls for papers and there is now a wider number of publication outlets for papers in this area than there has ever been.

These are very welcome developments, but it is not yet time for us to be resting on our laurels. The reality is that without a continued and explicit focus on the needs of the widest possible range of users, it is all too easy for those who most need assistance to be left behind. There have also been a number of backwards steps as well. Computer crime continues to grow as criminals develop ever-more sophisticated methods of scamming people. Remote access technologies are also proving vulnerable to criminal attack, such as the use of signal range extenders in a growing number of vehicle thefts.

\subsection{What does the future hold?}

While there continues to be a debate over how long Moore's Law can continue to hold [9], it is reasonable to expect that computing power will continue to increase for the foreseeable future even if the actual rate of growth is uncertain. It is also expected that form factors will continue to shrink. While Google Glass disappeared somewhat ignominiously, the prospect of truly wearable computing is clearly on the horizon. Furthermore, computers will become increasingly "intelligent" and "smart," however one may wish to define those terms. Machine learning and artificial intelligence are more commonplace than just a few years ago. 
The structure of future computer systems will also be far more ad hoc and flexible than in the past. The Internet of Things offers great potential for assembling a collection of sensors and actuators for almost any task imaginable, from refrigerators that tell you when you need to buy fresh milk to burglar alarms that message you to let you know there is a potential intruder [10].

What will not change, though, are the reasons for users to continue to access these new technologies. Although the environment is changing, the fundamental human needs evolve more slowly. Maslow’s hierarchy of needs still applies [11], i.e.:

- Physiological needs (heat, food, warmth, etc.)

- Safety needs (safety, security)

- Belongingness and love needs (intimate relationships, friends)

- Esteem needs (prestige and feeling of accomplishment)

- Self-actualisation (achieving ones full potential including creative activities)

These needs have been re-formulated over the years to include activities of daily living (ADLs), instrumental activities of daily living (IADLs) [12] and even areas of life endeavor [13].

Taking all of the above together, it is worth engaging in a bit of blue-sky thinking to consider what the principal challenges for the next 20 years may look like.

\section{The principal challenges for the future}

Taking Maslow's Hierarchy of Needs as a starting point, along with technological developments that we can reasonably foresee, a possible list of candidate areas of interest might look like the following:

- Applications of advanced machine learning/artificial intelligence

- Access to healthcare services/telehealth and extending independent living

- Personal mobility

- Robotic assistants and control of the environment

- Cybersecurity, physical security and privacy

- Access to work and education

- Access to full citizenship

- Communicating and socializing with friend and family

- Access to the latest technology

- Developing and using rapidly customizable and/or adaptable designs

- Personal recognition and self-worth

The rest of this paper will explore each of these areas. It is worth noting that the list above is not intended to be comprehensive, but instead seeks to inspire new avenues of research or to encourage readers to consider returning to some older paths that may be ready for a fresh perspective by taking advantage of the possibilities of new technological developments. 


\subsection{Applications of advanced machine learning/artificial intelligence}

The advent of artificial intelligence (AI) has opened the door to many new applications for computer-based applications. Advanced machine learning techniques allow computers to be trained swiftly on a broad range of data types. Combined together, it is no longer necessary for software developers to have to develop rigorous and fixed models and hierarchies of the world around us to allow computers to be programmed. This transition from a fixed algorithmic view of the world to a more flexible and nuanced understanding offers significant potential for developing computer systems that meet the needs of a wider range of users.

Take, for example, the development of the IBM Watson system [14]. Watson represents the cutting edge in natural language processing and deep question and answer (Q\&A) technology. The design intent was to develop a computer system that was inspired by the architecture and structure of the human brain and that could also provide sensible answers to flexibly structured questions asked using natural language. The system was put to the test in February 2011 when it competed against two Jeopardy! grand champions and triumphed. The newspaper coverage of this historic achievement was somewhat ambivalent, though, with a number of articles openly referencing the Terminator movies and the suggestion that the development of Watson was another step along the path towards a Skynet-type supercomputer capable of inflicting untold misery on the human race. The reality is that the applications of the Watson technology have been somewhat more mundane than global domination and enslavement of humankind. Artificial intelligence is one of those areas where public preconceptions and the reality of the technology are really quite out of step.

However, this should not be allowed to dissuade researchers from exploring the possibilities that AI offers for Universal Access. For example, rapid machine learning approaches can help train voice recognition software to recognize an individual person's speech patterns very quickly [15]. Combined with AI techniques to better eliminate background noise and interference, speech recognition systems offer the Star Trek view of computer interaction where members of the crew of the Enterprise can talk directly to the ship's computer. The rise of systems such as Siri, Cortana and Alexa show that such systems are on the verge of becoming commonplace. While such systems can still sometimes struggle with voices they have not been trained for, they are getting better with each new generation of the technology. The potential benefits for users with motor impairments, for example, to be able to speak to a computer rather than have to use their fingers and hands to do so are obvious.

Looking beyond the matter of physical access to computers, though, there are wider questions about what such technology could be used for. For example, while the Watson system is currently limited to the quality and size of the database on which it has been trained, it is easy to envisage a situation where such a system has been trained on a very large and quality-controlled dataset. Now imagine the situation where students are sitting in a classroom and their telephones have now become a gateway to the perfect question-and-answer system. Any question that they ask their telephone will be answered correctly and immediately. What are the implications of such a system being available to them? How will it change how they learn? How will 
it change how they are taught? It is known that the advent of electronic calculators had an adverse effect on how well people can perform mental arithmetic. A similar effect was seen with GPS systems and the ability to navigate. What will be the implications for learning in general if such a perfect question-and-answer system becomes universally available? [14]

These are all significant questions that need to be considered as new AI and machine-learning approaches are developed.

\subsection{Access to healthcare services/telehealth and extending independent living}

It is widely accepted that most developed countries have either an ageing or an aged population [16]. As people get older, they generally develop more health conditions that need either monitoring or medical interventions. The cost of providing this healthcare is growing, especially as the traditional family support structures that helped older adults in previous generations are becoming more geographically dispersed as family members move to new areas to find work. The costs of healthcare and social care, especially when an older adult has to be moved into a care home or hospital because their relatives cannot support them at home, are a major source of political debate and discussion as many countries are struggling to meet these demands and costs.

As a consequence, there is a clear role for technology to help ensure better access to healthcare services and also to help older adults maintain their ability to live independently for as long as possible.

In terms of access to healthcare, many GP practices now offer appointmentbooking services via the Internet. There is an increasing use of video calls, such as via Skype, for routine appointments or for regular check-ups. Internet-based pharmacies can deliver repeat prescriptions direct to a person's home. All of these services reduce pressures on GP practices. However, more can be done to automate as much of healthcare services as possible [17]. For instance, wearable sensors can be used to monitor blood sugar levels remotely that will send alerts automatically to healthcare providers when a dangerous blood sugar level is encountered.

Such technologies also extend a person's ability to continue to live independently for as long as possible as they offer peace of mind that help is on hand automatically should the worst happen. Staying in ones own home is not only better for society, as it is cheaper to support someone in their own home than in a care home or hospital, but also offers significant psychological and wellbeing benefits to the older adult [18].

The development of the Internet of Things technologies can help expand the range and type of sensors that can be used to help with healthcare and telehealth services. For example, one can envisage a scenario where each room in a house is equipped with high definition video cameras that are monitored either remotely or via an artificially intelligent computer system that is capable of identifying when a medical intervention is required. There is significant scope for research and development of new technologies that respect a person's privacy, but also allow them to remain in their own home for as long as possible. 


\subsection{Personal mobility}

Indivisible from the notion of independent living is the ability to move freely from one location to another without relying on the assistance of others [19]. Perhaps the ultimate epitome of this notion would be a fully autonomously controlled car that is wholly capable of driving itself without needing manual intervention at any point. While so-called "self-driving" cars are being tested, the reality is that they still require a licensed driver who is able to perform manual interventions when necessary. It is clear that the technology is still some distance away from the point where, say, a blind person could get into such a car, tell it a destination and then sit back to enjoy the ride.

However, even if such vehicles were available now, they would not solve all mobility issues. There are some places where private transport is either impractical or legally proscribed, such as many large city centres. Thus it is still necessary to ensure that public transport is also as accessible as possible. In a city such as London, many improvement have been made over recent years over bus timetabling, for example, where "smart" bus stops now show and speak the next few buses expected to arrive at that stop. Mobile phone apps also allow a person to monitor when buses are due. Trains, though, continue to be a major source of difficulty, with the $100+$ year old underground station infrastructure still not accessible to a person in a wheelchair at many tube stations.

There also remain challenges of personal mobility once someone has got out of their car or off public transport. It is still necessary to be able to navigate and walk or move oneself to get to many destinations, such as going into a particular shop or office building. The ubiquity of GPS systems offers great potential for helping with the navigation aspect of this, but there are still comparatively few genuinely accessible GPS systems available for, say, someone who is blind. Many smartphone-based navigation systems are pretty good in this regard, but still typically require the user to either look at the screen or hear the directions. For someone who is blind, the former is not a viable option. Hearing the instructions can work well, but may be at the expense of listening to surrounding traffic, etc., so may not be the safest option. Researchers have explored the possibility of vibrotactile navigation cues, but no such system has achieved commercial viability yet.

\subsection{Robotic assistants and control of the environment}

Controlling ones environment to ensure that it is safe, secure, warm and dry is a fundamental human need according to Maslow [11]. Home automation systems are becoming increasingly available and are much more sophisticated nowadays than the earlier attempts that often required long, difficult command line instructions [10]. Apps are available for everything from controlling the thermostat to monitoring burglar alarms. However, consumers are faced with a choice of either buying all the systems from the same supplier if they want a single unified interface to control everything, or having to download, install and use multiple apps, one for each system they wish to control. There is a clear need for a more unified approach that allows multiple 
systems to be controlled via a coherent interface design, somewhat akin to the Apple UI design guidelines adhered to by developers of software to run on Apple Macs.

Looking beyond home automation systems, robots to help people with functional impairments have been proposed and explored many times over the years. For example, robot guide (i.e. seeing eye) dogs have been explored by a number of different research groups. However, very few such robots have achieved commercial viability or market acceptance [20]. Those that have done so are either focused on very particular functions, such as the Handy 1 robot that allows a person with motor impairments to feed themselves, or are typically used in a medical situation, such as prostheses or post-stroke rehabilitation exercises.

Given that it is comparatively straightforward to include speech recognition and Internet connectivity into a robot using current technology, and that robots can be made increasingly lifelike such as the RoboThespian, perhaps now is the time to re-visit the possibility of personal robotic assistants. There is a clear role, for example, in helping older adults remain independent for such a robot [21].

\subsection{Cybersecurity, physical security and privacy}

Again, according to Maslow, security is a key human need, as is privacy. However, these are issues that are very rarely addressed in the field of universal access. Indeed, privacy is often assumed to be a low priority for many universal access solutions that depend upon users being willing to share information about themselves in the hope of gaining a better "experience" as a result. While it is generally considered that someone with a significant health issue is usually more willing to forego privacy to ensure better healthcare, it cannot be assumed to be true for all users with functional impairments or health issues. More work needs to be done on balancing the need to share information for better support with a person's fundamental right to privacy.

One solution is to explore methods of more informed consent. Another would be to employ more "local" intelligence so only significant information is shared beyond a user's area of personal control. So, for example, consider a robotic assistant in an older adult's home. The robot could be equipped with a camera and motion detection sensors to monitor whether the person is active. Its artificial intelligence could then determine whether the person's behaviour and actions fall within pre-determined acceptable parameters. If they do not, and only if they do not, the robot could then send a message to a monitoring station requesting assistance. However, if the behaviour and actions fall within the acceptable parameters, no information need be shared and the person's privacy is protected. In other words, by putting more local intelligence into the system, personal information can be held within a secure, ring-fenced domain (the person's home environment) and only shared with external agencies when medically necessary.

Another area needing further research is cybersecurity. Scammers and on-line criminals are becoming increasingly sophisticated in their tactics and techniques [22]. Initially such attacks were based on seeking financial gain, through approaches such as the infamous 419 scam. However, there are an increasing number of examples where physical thefts and damage are resulting from the activities of hackers and 
other criminals. The use of signal range extenders for breaking into cars with keyless remotes is one example. Another is the case of hackers gaining remote control of engine control units (ECUs) in cars. These security risks are bad enough for ablebodied users, but for someone with a functional impairment, the potential risks could be catastrophic. Imagine if a hacker took remote control of a powered wheelchair, for instance, or a medication-dispensing machine.

While security is generally considered in the design of most technologies, is sufficient attention being paid to the particular needs of those requiring universal access solutions? Very few papers in either the UAIS journal or the UAHCI conferences address this particular issue.

\subsection{Access to work and education}

Although not explicit in Maslow's hierarchy of needs, access to both education and work are essential parts of everyday life and this is as true for those with functional impairments as for anyone else [23]. This basic principle was recognized by organisations such as the Papworth Trust, which evolved from its early days as a tuberculosis colony to become a residential centre for those with severe motor and sensory impairments. Central to the philosophy of the Trust was that work was an essential part of any rehabilitation programme. The Trust ran a number of companies, from the famous Papworth Leather and Travel Goods, which made the suitcases used by the British royal family, to the Pendragon Press. It even ran its own vehicle repair shop. All of the residents at the Trust were given a job in one of the companies. This gave them all a sense of purpose and a sense of worth. Later the Trust evolved further to providing skills training so the residents could secure jobs in local companies.

A foundation to any attempt to access work is, of course, to be able to access education. While much of the research in universal access focuses on technologies that can facilitate access to education (such as research into computer access and the like), the development of assistive technologies (for conditions such as dyslexia and dyscalculia) and even the development of curricula for teaching designers how to develop more inclusive solutions [e.g. 23], there is comparatively little research into the design of curricula for people who are functionally impaired beyond usually simple guidelines. Research into cognitive and learning difficulties is also not as widespread as that into sensory or motor impairments [24].

\subsection{Access to full citizenship}

In the 2017 general election in the UK, there were five Members of Parliament who were classified as "disabled" out of 650 MPs. Given that it is generally accepted in 1 in 6 of the population has a functional impairment that generally affects their ability to undertake everyday activities [25, 26], 5 out of 650 cannot be considered representative of the population in general. It is symptomatic of level of participation in some aspects of citizenship for people with disabilities, though. How many debating programmes on television feature disabled people in the audience, for example? While there has been research into the accessibility of voting mechanisms, there have 
been very few papers exploring the level of participation in political debate or policymaking.

Other developments in society may also exclude people with functional impairments inadvertently [27]. For example, a recent newspaper article was examining the impact of the move to the so-called cashless society on older adults as an increasing number of companies move towards not accept cash payments. Such a move penalises those who are not comfortable with the new payment technologies and a disproportionate number of those who fall into this category are older adults. Thus another challenge is how to ensure that new developments of this type are genuinely inclusive and not driven by one segment of the population to the detriment of others [28, 29].

\subsection{Communicating and socializing with friends and family}

While there is an increasing variety of possible methods for communicating with friends and family, such as Skype, WhatsApp, FaceTime and the like, many charities still report that there is a very high number of people who feel isolated and alone. Just because the software is available, that does not mean that it is necessarily accessible to everyone.

Equally, a number of mental health professionals are concerned about the impact of social media on the wellbeing of vulnerable individuals, especially with the frequency of bullying and intimidating messages in some forums.

Thus while there may be many new mechanisms for communication, the issues of how to ensure fruitful, productive and healthy interaction have clearly not been solved for everyone.

\subsection{Access to the latest technology}

The issues around basic interaction science are still not fully resolved [30]. While there is a growing body of research into computer access there is still an unacceptably high number of people who experience difficulty interacting with a computer [31]. The development of new forms of technology, such as the advent of smartphones and tablets, offer opportunities and challenges to older adults and those with functional impairments. There is clearly still a need for more research into the fundamentals of human-computer interaction.

\subsection{Developing and using rapidly customizable and/or adaptable designs}

Additive manufacturing, commonly referred to as 3D printing, is frequently held up as an example of rapid prototyping and manufacturing technology. The age of truly personalized products is approaching rapidly [e.g. 32]. Such technology offers significant opportunity for those who do not conform to the usual anthropomorphic datasets. Such people include those who are notably taller or shorter than average, weaker or stronger, larger or slimmer. However, there are comparatively few commercial examples of such technology in use. One example is from skiing. Ski boots can be tailored to ones feet through the use of innovative thermoplastics that can be heated and 
moulded very rapidly - no different in principle to moulding plastic gum shields for contact sports. This is a very particular example though and only scratches the surface of what these new manufacturing technologies can support. Product designers can, in theory, develop modular kettles that can have handles attached that are 3D printed to the exact contours of ones hand. The challenge here is how best to take full advantage of this new technology and the possibilities it offers.

In the field of software design, developers can go one step further and produce software that is capable of adapting itself to the evolving needs of its users [33]. However, while the principles for accomplishing this are understood, very little commercial software supports such an approach. There is an obvious challenge here to get such principles accepted more widely.

\subsection{Personal recognition and self-worth}

It is difficult to envisage the development of a piece of new software or technology that is designed to improve ones recognition or sense of self-worth. However, what is clearly possible is developing a much better understanding of how we as individuals view and measure our sense of self-worth [34]. This is a continually-evolving notion. Where a few years ago, it may have been measured by the size of ones social circle, for example, these days it may include the number of virtual friends as well as those that we meet in real life.

It is important that designers and developers understand the value of self worth. Any successful design has to meet the needs, wants and aspirations of the users and be both practically and socially acceptable. The notion of "social" acceptance here includes the implicit impact on ones self-worth [35].

\section{Conclusions}

While there have been many significant developments since the inaugural UAHCI conference and first issue of the UAIS journal in 2001, there remain many notable challenges for researchers in the field of universal access to address. This paper has addressed how far technology has developed over the intervening periods and has also highlighted a number of those challenges that are worth exploring further.

\section{References}

1. Sears, A., Karat, CM., Oseitutu, K.: Productivity, satisfaction, and interaction strategies of individuals with spinal cord injuries and traditional users interacting with speech recognition software. International Journal on Universal Access in the Information Society (Springer). June, 1(1), 4-15 (2001). doi:10.1007/s102090100001

2. Stary, C.: User diversity and design representation: Towards increased effectiveness in Design for All. International Journal on Universal Access in the Information Society. June, 1(1), 16-30 (2001). doi:10.1007/s102090100002 
3. Fairhust, M., Ng, S.: Management of access through biometric control: A case study based on automatic signature verification. International Journal on Universal Access in the Information Society. June, 1(1), 31-39 (2001). doi:10.1007/s102090100009

4. Stephanidis, C., Savidis, A.: Universal access in the information society: Methods, tools, and interaction technologies. International Journal on Universal Access in the Information Society. June, 1(1), pp. 40-55 (2001). doi:10.1007/s102090100008

5. Jacko, J., Vitense, H.: A review and reappraisal of information technologies within a conceptual framework for individuals with disabilities. International Journal on Universal Access in the Information Society. June, 1(1), pp. 56-76 (2001). doi:10.1007/s102090100003

6. ADA: Americans with Disabilities Act. US Public Law 101-336 (1990).

7. DDA: Disability Discrimination Act, DfEE, London (1995).

8. UN: Convention on the Rights of Persons with Disabilities. United Nations (2006).

9. Bright, P.: Moore's Law really is dead this time. Ars Technica (2016). Available at: https://arstechnica.com/information-technology/2016/02/moores-law-really-is-dead-thistime/ last accessed 2019/02/05.

10. Keates, S., Bradley, D., Sapeluk, A.: The future of universal access? Merging computing, design and engineering. Universal Access in Human-Computer Interaction. Applications and Services for Quality of Life, LNCS, Springer-Verlag: Heidelberg, pp. 54-63 (2013). doi:10.1007/978-3-642-39194-1_7

11. Maslow, A.H.: A theory of human motivation. Psychological Review. 50(4), 370-96 (1943). doi:10.1037/h0054346

12. Bookman, A., Harrington, M., Pass, L., Reisner, E.: Family caregiver handbook. Cambridge, MA: Massachusetts Institute of Technology (2007).

13. Keates, S., Kozloski, J., Varker, P.: Cognitive impairments, HCI and daily living. Proceedings of International Conference on Universal Access in Human-Computer Interaction. LNCS, Vol. 5614. Springer-Verlag: Heidelberg, pp. 366-374 (2009). doi:10.1007/978-3642-02707-9_42.

14. Keates, S., Varker, P., Spowart, F.: Human-machine design considerations in advanced machine-learning systems. IEEE/IBM Journal of Research and Development, IEEE, 55(5) 4:1-4:10, September/October (2011). doi: 10.1147/JRD.2011.2163274

15. Kinch, M.W., Melis, W.J.C., Keates, S.: The benefits of contextual information for speech recognition systems. In: Proceedings of the 10th Computer Science and Electronic Engineering Conference (CEEC), 19 - 21 September 2018, University of Essex, Colchester, UK (2018).

16. Coleman, R.: Living longer. In: Clarkson, P.J., Coleman, R., Keates, S., Lebbon, C. (eds.) Inclusive Design: Design for the whole population, Springer-Verlag, Heidelberg, pp. 120141 (2003).

17. Ball, L., Szymkowiak, A., Keates, S., Bradley, D., Brownsell, S.: eHealth and the Internet of Things. In: Proceedings of the 3rd International Conference on Pervasive Embedded Computing and Communication Systems. SCITEPRESS, Barcelona, Spain, pp. 139-142, (2013). doi:10.5220/0004336701390142

18. Keates, S.: Design for the value of inclusiveness. In: Van den Hoven, J. Vermaas, P.E., van de Poel, I. (eds.) Handbook of Ethics, Values and Technological Design, SpringerVerlag, Heidelberg, pp. 383-402 (2014).

19. Coda, A., Gadeselli, R.: The FIAT Autonomy programme. In: Clarkson, P.J., Coleman, R., Keates, S., Lebbon, C. (eds.) Inclusive Design: Design for the whole population, SpringerVerlag, Heidelberg, pp. 216-224 (2003). 
20. Mahoney, R.: Robotic products for rehabilitation: Status and strategy. In: Proceedings of the 5th International Conference on Rehabilitation Robotics (ICORR '97), Bath, UK, pp. 12-17 (1997).

21. Keates, S., Kyberd, P.J.: Robotic assistants for universal access. In: Universal Access in Human-Computer Interaction. Human and Technological Environments. Proceedings of UAHCI 2017. (eds. Antona, M., Stephanidis, C.) LNCS vol. 10279, Springer, pp. 527-538 (2017). doi: 10.1007/978-3-319-58700-4_43

22. Hofman, C., Keates, S.: Countering brandjacking in the digital age - and other hidden risks to your brand. Springer-Verlag: London (2013)

23. Keates, S.: A pedagogical example of teaching Universal Access. International Journal on Universal Access in the Information Society (UAIS), Springer, 14 (1), 97-110 (2015). doi: 10.1007/s10209-014-0398-4

24. Keates, S., Adams, R., Bodine, C., Czaja, S., Gordon, W., Gregor, P., Hacker, E., Hanson, V., Kemp, J., Laff, M., Lewis, C., Pieper, M., Richards, J., Rose, D., Savidis, A., Schultz, G., Snayd, P., Trewin, S., Varker, P.: Cognitive and learning difficulties and how they affect access to IT systems. International Journal on Universal Access in the Information Society, Springer, 5(4), 329-339 (2007). doi:10.1007/s10209-006-0058-4

25. Grundy, E., Ahlburg, D., Ali, M., Breeze, E., Sloggett, A.: Disability in Great Britain. Department of Social Security, Research Report No. 94, Corporate Document Services, London, UK (1999).

26. Keates, S.: Designing for Accessibility: A business guide to countering design exclusion. Lawrence Erlbaum Associates/CRC Press: Mahwah, New Jersey (2007).

27. Keates, S. Clarkson, P.J.: Countering Design Exclusion: An introduction to inclusive design. Springer-Verlag: London (2003)

28. Keates, S., Lebbon, C., Clarkson, P.J.: Investigating industry attitudes to Universal Design. In: Proceedings of RESNA 2000, Orlando, FL. RESNAPress, pp. 276-278 (2000).

29. Dong, H., Keates, S., Clarkson, P.J., Cassim, J.: Implementing inclusive design: the discrepancy between theory and practice. Proceedings of the 2002 ERCIM Workshop on User Interfaces for All, Lecture Notes in Computer Science, vol. 2615, Springer, Berlin, pp. 106-117 (2002). doi:10.1007/3-540-36572-9_8

30. Keates, S.: When Universal Access is not quite universal enough: Case studies and lessons to be learned. International Journal on Universal Access in the Information Society, Springer Online First (2018). doi:10.1007/s10209-018-0636-2

31. Keates, S., Robinson, P.: Gestures and multimodal input. Behaviour and Information Technology, Taylor and Francis Ltd. January-February, 18(1), 36-44 (1999). doi: 10.1080/014492999119237

32. Gao, J., El Souri, M., Keates, S.: Advances in manufacturing technology Vol. 31. IOS Press: Amsterdam (2017)

33. Stephanidis, C.: The Universal Access handbook. CRC Press: Boca Raton, FL (2009).

34. Yelding D: Power to the people. In: Clarkson, P.J., Coleman, R., Keates, S., Lebbon, C. (eds.) Inclusive Design: Design for the whole population, Springer-Verlag, Heidelberg, pp. 104-117 (2003)

35. Nielsen, J.: Usability engineering. Morgan Kaufmann, San Francisco, CA (1994). 